\title{
Liver involvement in subjects with rheumatic disease
}

\author{
Carlo Selmi', Maria De Santis ${ }^{1}$ and M Eric Gershwin²*
}

\begin{abstract}
The liver is often overlooked as a target organ, with pathology either secondary to an underlying disease or due to the toxicity of therapies and the medical complications of extrahepatic diseases. It is thus important for the clinical rheumatologist to be aware of the diagnostic procedure to monitor liver injury. Indeed, systemic rheumatologic diseases may be associated with liver abnormalities secondary to the presence of a coexisting autoimmune liver disease (particularly primary biliary cirrhosis or autoimmune hepatitis), the direct involvement of the liver parenchyma, or the impact of medical treatments (particularly methotrexate) on the liver. In addition, the rheumatologist should be aware of the impact of immunosuppressive agents on underlying viral infections, particularly viral hepatitis. We review herein the data on the role of the liver in the clinical management of systemic rheumatic diseases.
\end{abstract}

\section{Introduction}

The liver is amongst the largest lymphoid organs and acts not only as a site of tolerance but also as a primary line of defense in mucosal immunobiology [1]. Additionally, there is a critical interplay within the liver between the primary role of protection against infections and the seemingly contrary role of maintaining tolerance. This interplay becomes particularly important in the case of chronic viral hepatitis, in which the immune response often becomes relatively ineffective. In contrast, there is increasing evidence for the critical role of the liver in modulating the immune response in autoimmune and chronic inflammatory diseases [2-4]. This is represented by the central role of the liver microcirculation in

\footnotetext{
*Correspondence: megershwin@ucdavis.edu

2Division of Rheumatology, Allergy and Clinical Immunology, University of California at Davis School of Medicine, 451 E. Health Sciences Drive, Suite 6510 Davis, CA 95616, USA

Full list of author information is available at the end of the article
}

maintaining immune tolerance while initiating an adequate response to infectious agents; examples of the implications of these phenomena are illustrated by the putative role of molecular mimicry in the onset of autoimmune diseases [1].

A wide spectrum of rheumatic diseases can affect the liver with various degrees of involvement and histopathological features; these features are not specific to such comorbidities and are based on clinical features that are common to other chronic liver diseases [5]. In contrast, the primary immune diseases of the liver are autoimmune hepatitis (AIH) [6], primary biliary cirrhosis (PBC) [7], and primary sclerosing cholangitis (PSC) [8]. These three major autoimmune liver diseases have prevalence rates of 100 cases per million (AIH), 400 cases per million (PBC), and 150 cases per million (PSC) [9]. PBC and PSC are primarily biliary/cholestatic diseases with involvement of liver parenchyma only as a secondary manifestation; as such, their liver biochemistry profile reflects cholestasis. $\mathrm{AIH}$ results from hepatocyte damage with a typical hepatitis pattern of liver tests.

\section{Liver histology for the rheumatologist}

Liver involvement in patients with rheumatic disease manifests typical, although not specific, histopathological features that may pose a dilemma with primary liver conditions [10]. The typical liver histology of AIH [11] includes portal-parenchymal interface hepatitis with abundant lymphocyte and plasma cell infiltrates that cross the limiting plate and invade the liver parenchyma [6], while focal intrahepatic small bile duct obliteration and granulomas are typical of $\mathrm{PBC}$ [12] together with portal inflammation, subsequent periportal hepatitis, fibrous septa, bridging necrosis and, ultimately, frank cirrhosis. PSC can affect bile ducts of any size and is thus characterized by damage, atrophy, and loss of medium and large-size bile ducts within or outside the liver, leading to concentric periductal fibrosis and obliteration of bile ducts [8]; in the case of small-duct PSC, only liver histology can provide evidence in the diagnostic process.

Liver histology is not peculiar in systemic rheumatic diseases with hepatic involvement, and different patterns can be observed in patients with liver enzyme 
Table 1. Histopathology of liver involvement in systemic rheumatic diseases

\begin{tabular}{ll}
\hline Histological definition & Features \\
\hline Chronic active hepatitis & Piecemeal necrosis with mononuclear cell infiltrate \\
Chronic persistent hepatitis & Chronic inflammatory infiltration of the portal tract with preserved lobular architecture and without portal fibrosis \\
Cirrhosis & Diffuse liver degeneration characterized by fibrous tissue and regenerative nodules \\
Fibrosis & Abnormal production of fibrous tissue in response to liver injury \\
Steatosis & Abnormal retention of lipids within hepatocytes \\
Cholangitis & Inflammation of bile ducts \\
Reactive hepatitis & Aspecific and mild inflammatory cell infiltrate of portal spaces \\
Nodular regenerative hyperplasia & Diffuse nodularity of the liver without fibrosis \\
Granulomas & Aggregate of epithelioid cells surrounded by lymphocytes \\
Idiopathic portal hypertension & Increased blood pressure in the veins of the portal system not due to liver diseases \\
Arteritis & Vessel wall inflammation \\
Giant cell hepatitis & Presence throughout the liver of enlarged multinucleated hepatocytes with abundant cytoplasm \\
Massive hepatic necrosis & Diffuse hepatocyte necrosis \\
\hline
\end{tabular}

abnormalities undergoing liver biopsy or in autoptical studies. The common histological features are summarized in Table 1. Chronic active hepatitis, chronic persistent hepatitis, cirrhosis, nodular regenerative hyperplasia, fibrosis, steatosis, and granulomas are the major findings reported in rheumatic diseases, along with less specific findings such as mild chronic inflammatory cell infiltrate of the portal space $[13,14]$. Vascular involvement is not uncommon and has been described as intrahepatic small vessel arteritis, Budd-Chiari syndrome, or isolated portal hypertension. Drug-induced liver injury is significantly more frequent than primary disease-related liver involvement and concurrent viral hepatitis or opportunistic infections have to be ruled out in rheumatic patients. Finally, amyloidosis is a rare cause of liver involvement in chronic systemic rheumatic diseases [15].

\section{The liver and connective tissue disease}

Liver involvement in connective tissue diseases is not uncommon, but the liver is not the major organ target. In systemic lupus erythematosus (SLE), systemic sclerosis (SSc), and primary Sjögren's syndrome (pSS), serologic liver dysfunction and histological lesions have been described in numerous descriptive studies mostly based on case series.

Abnormal liver function tests are common in patients with SLE - being reported in 3 to $29 \%$ of the patients [14], often during disease exacerbations [16]. Numerous histopathological patterns can be found in liver biopsies of SLE patients, including small artery vasculitis reported in up to $21 \%$ of the patients [17], nonalcoholic fatty liver diseases in 20 to $73 \%$, nodular regenerative hyperplasia in $5.7 \%$, chronic persistent or active hepatitis in $2.4 \%$, and cirrhosis in $1.1 \%$ or fibrosis in $0.8 \%[17,18]$. Moreover, anecdotal cases of giant cell hepatitis, granulomatous hepatitis, massive hepatic necrosis, cholangitis, isolated portal hypertension, Budd-Chiari syndrome, and liver infarction have also been described. End-stage liver disease is a very infrequent finding [14], while cases of Budd-Chiari syndrome have been reported in association with antiphospholipid syndrome. Moreover, antiphospholipid antibodies have been shown to be involved in small artery intrahepatic damage and in the pathogenesis of nodular regenerative hyperplasia.

Gastrointestinal involvement occurs invariably in SSc. In a large cohort of patients, some minor degree of liver involvement has been reported in $1.1 \%$ of the cases while at autopsy liver fibrosis was found in $8.8 \%$ of patients, slightly more prevalent compared with non-SSc controls [19]. The association between SSc and PBC is more significant and a common pathogenetic trait has been suggested [20].

Finally, liver involvement is considered the most common non-exocrine feature in pSS [14,21], presenting as abnormal liver function tests in 27 to $49 \%$ of the patients [22]. In two-thirds of the cases cholestasis is found at liver biochemistry, and in up to $50 \%$ of cases AIH or PBC is associated with pSS. When presenting as a primary disease-related internal organ involvement, liver disease in pSS is associated with inflammation markers similar to other systemic manifestations of the diseases [23].

\section{The liver and vasculitis}

Vasculitis can affect every organ of the digestive system but the liver is not commonly involved. Liver involvement is limited to polymyalgia/Horton's arteritis, polyarteritis nodosa, Wegener's granulomatosis, and Behçet's disease [24]. Abnormal liver function tests commonly manifest a cholestatic pattern with elevated alkaline phosphatase and $\gamma$-glutamyl transferase levels that characterize up to 
$62 \%$ of patients with rheumatic polymyalgia [25]. Polymyalgic patients with elevated liver enzymes have an increased risk to develop Horton's arteritis [26].

Liver involvement occurs in a variable proportion (16 to $56 \%$ ) of patients affected by polyarteritis nodosa, although clinical manifestations related to liver disease are quite rare; conversely, necrotizing arteritis of the liver has been found in the vast majority of patients with polyarteritis [27]. Liver injury is rare in Wegener's granulomatosis. Both granulomatous necrotizing hepatic involvement and mild nonspecific lobular hepatitis have been described. Liver involvement is rarely observed in patients with Behçet's disease, with a predominance of Budd-Chiari syndrome.

\section{The liver and arthritis}

Among patients with arthritis, hepatic involvement has been reported only in cases of rheumatoid arthritis (RA) and its variants. Nevertheless, liver injury is not generally recognized as a significant extra-articular feature of RA. Abnormal liver tests varying with disease activity, mainly elevated alkaline phosphatase, have been reported in 18 to $50 \%$ of patients with RA. Similarly, $65 \%$ of unselected patients with RA had abnormal liver biopsies - one-half having mild portal chronic inflammatory infiltrate of the portal tract and small foci of necrosis, and one in four having fatty liver [28]. As in SLE, drug-induced liver injury is frequent in RA, especially during nonsteroidal anti-inflammatory drug (NSAID) and methotrexate treatments. Liver involvement has also been reported in Felty's syndrome as liver enlargement (68\%) and a rise in alkaline phosphatase (25\%). Liver histology demonstrates diffuse lymphocyte infiltrate, periportal fibrosis with lymphocytic infiltration, and portal hypertension. Liver enlargement and elevated aminotransferases have also been reported in adult-onset Still's diseases, while liver biopsies have demonstrated aspecific mild portal infiltrate of limited significance [29]. Cases of acute liver failure, however, have also been reported.

\section{The liver and overlap syndromes}

Patients with signs and symptoms of two or more immunologic diseases are considered as having overlap syndromes. Overlap syndromes may include AIH and PBC or PSC, as largely reported in the literature (illustrated in Table 2); patients with overlap syndromes manifest both hepatitis and cholestatic biochemical profiles and histological features suggestive of $\mathrm{AIH}$ and $\mathrm{PBC}$ or PSC. AIH and PBC overlap syndrome has been reported in almost $10 \%$ of adults with $\mathrm{AIH}$ or $\mathrm{PBC}$, whereas AIH and PSC overlap syndrome has been found in 1.4 to $49 \%$ of children, adolescents, and young adults with AIH or PSC. Transition from one to another liver disease is sometimes possible in a time frame of months
Table 2. Prevalence of liver disease overlap syndromes in selected rheumatic patients

\begin{tabular}{lcccc}
\hline & AlH & PBC & PSC & References \\
\hline AlH & - & 4.2 to $9 \%$ & 1.4 to $49.1 \%$ & {$[30]$} \\
SLE & 2.7 to $20 \%$ & 2.7 to $15 \%$ & 1 case & {$[18,27,31]$} \\
pSS & 6 to $47 \%$ & 35 to $57 \%$ & 11 cases & {$[31,34,35]$} \\
SSC & 11 cases & $51.2 \%$ & 1 case & {$[31-33]$} \\
\hline
\end{tabular}

$\mathrm{AlH}$, autoimmune hepatitis; PBC, primary biliary cirrhosis; PSC, primary sclerosing cholangitis; pSS, primary Sjögren's syndrome; SLE, systemic lupus erythematosus; SSc, systemic sclerosis.

to years [30]. While cases of anti-mitochondrial antibody-negative $\mathrm{PBC}$ and $\mathrm{AIH}$ overlap syndromes have been described, there is no clear evidence for the existence of a PBC/PSC overlap syndrome. In addition, $\mathrm{AIH}$ and $\mathrm{PBC}$ overlap syndrome has been described in patients with SLE, SSc, and pSS [31].

$\mathrm{AIH}, \mathrm{PBC}$, and PSC may develop in patients with systemic rheumatic diseases (Table 2). The accurate prevalence of overlap diseases is unknown because of a variety of flaws encountered in the available prevalence studies. The majority of data reported only case reports, while in case series the liver histology is derived from autoptical investigations or liver biopsies performed on selected patients frequently with liver enzyme abnormalities.

While in patients with SLE the prevalence of AIH and PBC seems similar among patients with liver abnormalities, in SSc patients PBC has been reported in $51.2 \%$ of the cases with liver dysfunction [32] and in more than 50\% of patients with a CREST (calcinosis, Raynaud, esophagopathy, sclerodactily, teleangectasia) variant [33], and AIH is rare - only 11 cases have been reported - while only one case of SSc/PSC comorbidity has been described.

A higher frequency of $\mathrm{AIH}$ and $\mathrm{PBC}$ has been reported in pSS patients with liver dysfunction undergoing hepatic biopsies: these rates ranged between 6 and 47\% and between 35 and 57\%, respectively [34]. Eleven cases of SS and PSC have been published and all of the patients also had chronic pancreatitis, while in our series SS was a frequent comorbidity condition in $\mathrm{PBC}$ cases [35]. A vast number of single case reports are available. As an example, AIH has been described in polymyositis/ dermatomyositis, RA, Still's disease, polymyalgia, and polyarteritis nodosa [36]. On the other hand, $\mathrm{PBC}$ has been described in polymyositis/dermatomyositis, RA, Still's disease, polymyalgia, Churg-Strauss's disease, microscopic polyangiitis, Behcet's disease, and SchonleinHenoch purpura. Finally, PSC has been exceptionally reported in association with rheumatic diseases.

\section{The liver and medical therapies in rheumatology}

Therapeutic strategies for the treatment of autoimmune liver disease are essentially based on corticosteroids and 
immunosuppressant drugs such as methotrexate and azathioprine. The exception is provided by $\mathrm{PBC}$, for which ursodeoxycholic acid (UDCA) is the only established treatment [37]. The combination of UDCA and immunosuppressants, albeit rational, failed to prove effective or sufficiently safe in most cases. Conversely, methotrexate has been shown to be virtually void from consistent adverse effects in the treatment of real-life patients with or without concomitant UDCA [38] while being burdened by significant side effects in randomized clinical trials [39]. A simpler scenario is provided by AIH, for which corticosteroids represent the cornerstone of currently utilized regimens [40]. This treatment should be considered for all patients with AIH regardless of the disease activity at presentation and should be continued until 24 months to achieve normalization of liver tests and, ideally, resolution of liver inflammatory infiltrate at histology. In cases of incomplete response or relapse, a long-term maintenance regimen with azathioprine is justified. Salvage therapy includes cyclosporine or mycophenolate mofetil, although more solid data are awaited [40] and new frontier therapeutic approaches may prove beneficial [41].

Management of overlap syndromes between PBC and $\mathrm{AIH}$ is empirical and guided by the predominant manifestations of the disease. Indeed, patients with $\mathrm{AIH}$ and PBC with higher serum alkaline phosphatase and transaminases are candidates for treatment with corticosteroids and UDCA [42].

Of note, potential benefits have been proposed for antiTNF $\alpha$ treatments in autoimmune liver diseases although human data are scanty. In a murine model, anti-TNF $\alpha$ antibodies proved to be effective in reducing liver inflammation, necrosis, and fibrosis. Reports on the impact of anti-TNF $\alpha$ therapy in patients with inflammatory bowel diseases or other rheumatologic diseases and concomitant liver diseases [43] demonstrated potential benefits for nonalcoholic steatohepatitis and PSC; however, AIH and hepatosplenic T-cell lymphoma have also been reported [43].

Several are the implications of concomitant liver disease for the therapeutic intervention in rheumatologic diseases; in fact, the liver is frequently involved in the adverse events of systemic treatments utilized in rheumatology. A complete discussion goes beyond the aims of the present review article, but it is easy to foresee that hepatitis virus reactivation and drug-related liver injuries are rapidly becoming a major cause for liver involvement in rheumatology with the use of more potent immunosuppressants such as biologics $[44,45]$ or hematopoietic stem cell transplantation [46]. Detailed recommendations on the use of immunomodulatory molecules in patients with chronic liver disease were reported by the American College of Rheumatology in 2008 for RA [47] while the
American Association for the Study of Liver Diseases also presented practice guidelines in 2009 for the management of patients with hepatitis B virus (HBV) or hepatitis $\mathrm{C}$ virus (HCV) chronic infection needing immunosuppressive therapy $[48,49]$, and clinical guidelines are available for viral hepatitis and inflammatory bowel disease treatment [50]. These guidelines support the view that the alanine aminotransferase (ALT) level, anti-HBsAg, anti-HBsAb, anti-HBcAb IgG and, in selected cases, HBV DNA, along with anti-HCV antibodies and HCV RNA, should be tested before an immunosuppressant treatment is initiated [47,50,51]. Currently, a preventive antiviral treatment is recommended in patients with an active chronic HBV infection (HBsAg-positive, elevated ALT and serum HBV DNA levels $>2,000 \mathrm{IU} / \mathrm{ml}$ ) and in patients with chronic HCV infections without extrahepatic contraindications $[47,50]$.

Prophylactic treatment is recommended in patients needing nonbiologic or biologic disease-modifying antirheumatic drugs with inactive HBV (HBsAg-positive, normal ALT and HBV DNA <2,000 IU/ml; or HBsAgnegative and anti-HBcAb-positive with or without HBsAb, normal ALT and HBV DNA $<50 \mathrm{IU} / \mathrm{ml}$ ), and to be considered in resolved $\mathrm{HBV}$ infection (HBsAgnegative, HBsAb-positive and/or anti-HBcAb-positive, normal ALT and HBV DNA $<50 \mathrm{IU} / \mathrm{ml}$ ) together with monitoring of ALT levels and serum HBV DNA in cases of long-term lamivudine use [47,50]. Disease-modifying antirheumatic drugs such as methotrexate and leflunomide are contraindicated in cirrhosis secondary to chronic HBV and HCV infections, whether treated or untreated, for all Child-Pugh stages [47], while biologics are contraindicated in both chronic HBV and HCV, whether treated or untreated, for those with significant liver injury, defined as chronic Child-Pugh classes B or C [47]. Immunosuppressant regimens including glucocorticoids appear to have the highest risk of HBV reactivation and $\mathrm{HCV}$ replication, so steroid-sparing treatment should be adopted when possible although low doses appear to be safe [48]. Finally, the use of NSAIDs should be carefully evaluated in patients with liver cirrhosis regardless of the etiology based on the risk of renal injury secondary to tubular ischemia. Referral clinical immunology textbooks report the risk of liver injury related to the use of classical anti-inflammatory treatments such as acetaminophen, NSAIDs, or methotrexate despite the rarity of such events in clinical trials [52].

The American College of Rheumatology guidelines indicate that when the levels of ALT are greater than twofold the upper normal limit, the initiation of diseasemodifying antirheumatic drugs such as methotrexate, leflunomide, and sulfasalazine is contraindicated, while recommendations on when to discontinue the drug are not provided [47]. Further, recent prospective data put 
such risk in a more accurate perspective. As an example, the risk of liver injury following acetaminophen intake is now well defined and recognizes a dose-dependent increase, with doses as high as $4 \mathrm{~g}$ /day proven to be safe in patients with chronic viral hepatitis or recent alcohol abuse as well as in patients with compensated liver cirrhosis [53]. Conversely, the appearance of NSAIDinduced liver injury appears to be dose independent while the new scenarios of biologic-induced autoimmune hepatitis [54] will warrant further studies on the longterm outcomes. A most recent study on the impact of methotrexate on liver function tests demonstrated a reasonably safe profile for this medication if properly used [55], thus suggesting that dedicated studies are necessary to detect the detrimental potential of immunomodulatory treatments. The issue of drug-induced liver injury became important with the discovery of the possible implications of occult hepatitis B infection [56] and the subsequent impact on the widespread use of monoclonal antibodies [57] in carriers and cases of chronic infections [58]. Finally, we should expect that the use of hematopoietic stem cell transplantation will also impact liver biology $[59,60]$.

\section{The liver in the present and future of rheumatology} Among patients with systemic rheumatic diseases, those with connective tissue diseases may present a mild liver involvement mainly related to the underlying disease activity that is, subsequently, transient. Progressive liver involvement is generally related to the coexistence of viral hepatitis or autoimmune liver diseases with obviously opposite results of the proposed systemic immunosuppressive treatments. Overlap diseases should be considered once hepatitic and/or cholestatic biochemical profiles, either simultaneously or consecutively, are not clearly explained by liver involvement of a rheumatic disease or by coincidental infection or drug toxicity. Finally, we encourage perspective studies to determine the impact in clinical practice of old and new treatments on the liver biology to overcome ancient beliefs [61] and pave the way for the new exciting developments in the field of biologics [62].

This article is part of the series Comorbid conditions in subjects with rheumatic diseases, edited by Daniel Aletaha and Thomas Dörner Other articles in this series can be found at http://arthritis-research.com/series/comorbid

\section{Abbreviations}

AlH, autoimmune hepatitis; ALT, alanine aminotransferase: HBV, hepatitis $B$ virus; $H C V$, hepatitis $C$ virus; NSAID, nonsteroidal anti-inflammatory drug; PBC, primary biliary cirrhosis; PSC, primary sclerosing cholangitis; pSS, primary Sjögren's syndrome; RA, rheumatoid arthritis; SLE, systemic lupus erythematosus; SSC, systemic sclerosis; TNF, tumor necrosis factor; UCDA, ursodeoxycholic acid.

\section{Author details}

'Department of Medicine and Autoimmunity and Metabolism Unit, IRCCS-Istituto Clinico Humanitas, University of Milan, via. A. Manzoni 56, 20089 Rozzano (MI), Italy. ${ }^{2}$ Division of Rheumatology, Allergy and Clinical Immunology, University of California at Davis School of Medicine, 451 E. Health Sciences Drive, Suite 6510, Davis, CA 95616, USA

\section{Competing interests}

The authors declare that they have no competing interests.

Published: 30 June 2011

\section{References}

1. Selmi C, Mackay IR, Gershwin ME: The immunological milieu of the liver. Semin Liver Dis 2007, 27:129-139.

2. Zhou P, Wirthlin L, McGee J, Annett G, Nolta J: Contribution of human hematopoietic stem cells to liver repair. Semin Immunopathol 2009, 31:411-419.

3. Padgett KA, Lan RY, Leung PC, Lleo A, Dawson K, Pfeiff J, Mao TK, Coppel RL, Ansari AA, Gershwin ME: Primary biliary cirrhosis is associated with altered hepatic microRNA expression. J Autoimmun 2009, 32:246-253.

4. Tiegs $\mathrm{G}$, Lohse AW: Immune tolerance: what is unique about the liver. J Autoimmun 2010, 34:1-6.

5. Invernizzi P: Geoepidemiology of autoimmune liver diseases. J Autoimmun 2010, 34:J300-J306

6. Vergani D, Longhi MS, Bogdanos DP, Ma Y, Mieli-Vergani G: Autoimmune hepatitis. Semin Immunopathol 2009, 31:421-435.

7. Invernizzi P, Selmi C, Poli F, Frison S, Floreani A, Alvaro D, Almasio P, Rosina F, Marzioni M, Fabris L, Muratori L, Qi L, Seldin MF, Gershwin ME, Podda M, Andreoletti M, Andriulli A, Baldini V, Battezzati PM, Benedetti A, Bernuzzi F, Bianchi FB, Bianchi I, Bignotto M, Bragazzi MC, Brunetto M, Caimi M, Caliari L, Caporaso N, Casella G, et al:: Human leukocyte antigen polymorphisms in Italian primary biliary cirrhosis: a multicenter study of 664 patients and 1992 healthy controls. Hepatology 2008, 48:1906-1912.

8. Aron JH, Bowlus CL: The immunobiology of primary sclerosing cholangitis. Semin Immunopathol 2009, 31:383-397.

9. Selmi C, Invernizzi P, Zuin M, Podda M, Gershwin ME: Genetics and geoepidemiology of primary biliary cirrhosis: following the footprints to disease etiology. Semin Liver Dis 2005, 25:265-280.

10. Rockey DC, Caldwell SH, Goodman ZD, Nelson RC, Smith AD: Liver biopsy. Hepatology 2009, 49:1017-1044.

11. Longhi MS, Ma Y, Mieli-Vergani G, Vergani D: Aetiopathogenesis of autoimmune hepatitis. J Autoimmun 2010, 34:7-14.

12. Hohenester $S$, Oude-Elferink RP, Beuers U: Primary biliary cirrhosis. Semin Immunopathol 2009, 31:283-307.

13. Youssef WI, Tavill AS: Connective tissue diseases and the liver. J Clin Gastroenterol 2002, 35:345-349.

14. Abraham S, Begum S, Isenberg D: Hepatic manifestations of autoimmune rheumatic diseases. Ann Rheum Dis 2004, 63:123-129.

15. Fix OK, Damon LE, Bass NM: Amyloidosis localized to the liver. Clin Gastroenterol Hepatol 2007, 5:e7.

16. Runyon BA, LaBrecque DR, Anuras S: The spectrum of liver disease in systemic lupus erythematosus. Report of 33 histologically-proved cases and review of the literature. Am J Med 1980, 69:187-194.

17. Matsumoto T, Yoshimine T, Shimouchi K, Shiotu H, Kuwabara N, Fukuda Y, Hoshi T: The liver in systemic lupus erythematosus: pathologic analysis of 52 cases and review of Japanese Autopsy Registry Data. Hum Pathol 1992, 23:1151-1158

18. Chowdhary VR, Crowson CS, Poterucha JJ, Moder KG: Liver involvement in systemic lupus erythematosus: case review of 40 patients. J Rheumatol 2008, 35:2159-2164.

19. D'Angelo WA, Fries JF, Masi AT, Shulman LE: Pathologic observations in systemic sclerosis (scleroderma). A study of fifty-eight autopsy cases and fifty-eight matched controls. Am J Med 1969, 46:428-440.

20. Tsuneyama K, Harada K, Katayanagi K, Watanabe K, Kurumaya H, Minato H, Nakanuma Y: Overlap of idiopathic portal hypertension and scleroderma: report of two autopsy cases and a review of literature. $J$ Gastroenterol Hepatol 2002, 17:217-223.

21. Kaplan MJ, Ike RW: The liver is a common non-exocrine target in primary Sjogren's syndrome: a retrospective review. BMC Gastroentero/ 2002, 2:21.

22. Kita H, Naidenko OV, Kronenberg M, Ansari AA, Rogers P, He XS, Koning F, 
Mikayama T, Van De Water J, Coppel RL, Kaplan M, Gershwin ME: Quantitation and phenotypic analysis of natural killer T cells in primary biliary cirrhosis using a human CD1d tetramer. Gastroenterology 2002, 123:1031-1043.

23. Chiorini JA, Cihakova D, Ouellette CE, Caturegli P: Sjogren syndrome: advances in the pathogenesis from animal models. J Autoimmun 2009, 33:190-196.

24. Mendes D, Correia M, Barbedo M, Vaio T, Mota M, Goncalves O, Valente J: Behcet's disease - a contemporary review. J Autoimmun 2009, 32:178-188,

25. von Knorring J, Wassatjerna C: Liver involvement in polymyalgia rheumatica. Scand J Rheumatol 1976, 5:197-204.

26. Rodriguez-Valverde V, Sarabia JM, Gonzalez-Gay MA, Figueroa M, Armona J, Blanco R, Fernandez-Sueiro JL, Martinez-Taboada VM: Risk factors and predictive models of giant cell arteritis in polymyalgia rheumatica. Am J Med 1997, 102:331-336.

27. Matsumoto T, Kobayashi S, Shimizu H, Nakajima M, Watanabe S, Kitami N, Sato $\mathrm{N}$, Abe H, Aoki Y, Hoshi T, Hashimoto H: The liver in collagen diseases: pathologic study of 160 cases with particular reference to hepatic arteritis, primary biliary cirrhosis, autoimmune hepatitis and nodular regenerative hyperplasia of the liver. Liver 2000, 20:366-373.

28. Ruderman EM, Crawford JM, Maier A, Liu JJ, Gravallese EM, Weinblatt ME: Histologic liver abnormalities in an autopsy series of patients with rheumatoid arthritis. Br J Rheumatol 1997, 36:210-213.

29. Andres $E$, Locatelli F, Pflumio F, Marcellin L: Liver biopsy is not useful in the diagnosis of adult Still's disease. QJM 2001, 94:568-569.

30. Poupon R, Chazouilleres O, Corpechot C, Chretien Y: Development of autoimmune hepatitis in patients with typical primary biliary cirrhosis. Hepatology 2006, 44:85-90

31. Efe C, Ozaslan E, Nasiroglu N, Tunca H, Purnak T, Altiparmak E: The development of autoimmune hepatitis and primary biliary cirrhosis overlap syndrome during the course of connective tissue diseases: report of three cases and review of the literature. Dig Dis Sci 2010, 55:2417-2421.

32. Assassi S, Fritzler MJ, Arnett FC, Norman GL, Shah KR, Gourh P, Manek N, Perry M, Ganesh D, Rahbar MH, Mayes MD: Primary biliary cirrhosis (PBC), PBC autoantibodies, and hepatic parameter abnormalities in a large population of systemic sclerosis patients. J Rheumatol 2009, 36:2250-2256.

33. Akiyama Y, Tanaka M, Takeishi M, Adachi D, Mimori A, Suzuki T: Clinical, serological and genetic study in patients with CREST syndrome. Intern Med 2000, 39:451-456.

34. Hatzis GS, Fragoulis GE, Karatzaferis A, Delladetsima I, Barbatis C, Moutsopoulos HM: Prevalence and longterm course of primary biliary cirrhosis in primary Sjogren's syndrome. J Rheumatol 2008, 35:2012-2016.

35. Gershwin ME, Selmi C, Worman HJ, Gold EB, Watnik M, Utts J, Lindor KD, Kaplan MM, Vierling JM: Risk factors and comorbidities in primary biliary cirrhosis: a controlled interview-based study of 1032 patients. Hepatology 2005, 42:1194-1202

36. Teufel A, Weinmann A, Kahaly GJ, Centner C, Piendl A, Worns M, Lohse AW, Galle PR, Kanzler S: Concurrent autoimmune diseases in patients with autoimmune hepatitis. J Clin Gastroenterol 2010, 44:208-213.

37. Selmi C, Podda M: Methotrexate for primary biliary cirrhosis: who is to be trusted? Dig Dis Sci 2010, 55:3013-3015.

38. Kaplan MM, Bonder A, Ruthazer R, Bonis PA: Methotrexate in patients with primary biliary cirrhosis who respond incompletely to treatment with ursodeoxycholic acid. Dig Dis Sci 2010, 55:3207-3217.

39. Combes B, Emerson SS, Flye NL, Munoz SJ, Luketic VA, Mayo MJ, McCashland TM, Zetterman RK, Peters MG, Di Bisceglie AM, Benner KG, Kowdley KV, Carithers RL Jr, Rosoff L Jr, Garcia-Tsao G, Boyer JL, Boyer TD, Martinez EJ, Bass NM, Lake JR, Barnes DS, Bonacini M, Lindsay KL, Mills AS, Markin RS, Rubin R, West AB, Wheeler DE, Contos MJ, Hofmann AF: Methotrexate (MTX) plus ursodeoxycholic acid (UDCA) in the treatment of primary biliary cirrhosis. Hepatology 2005, 42:1 184-1193.

40. Manns MP, Czaja AJ, Gorham JD, Krawitt EL, Mieli-Vergani G, Vergani D, Vierling JM: Diagnosis and management of autoimmune hepatitis. Hepatology 2010, 51:2193-2213

41. Longhi MS, Meda F, Wang P, Samyn M, Mieli-Vergani G, Vergani D, Ma Y: Expansion and de novo generation of potentially therapeutic regulatory T cells in patients with autoimmune hepatitis. Hepatology 2008, 47:581-591.

42. Boberg KM, Chapman RW, Hirschfield GM, Lohse AW, Manns MP, Schrumpf E: Overlap syndromes: the International Autoimmune Hepatitis Group (IAIHG) position statement on a controversial issue. J Hepatol 2011 , 54:374-385.
43. Coffin CS, Fraser HF, Panaccione R, Ghosh S: Liver diseases associated with anti-tumor necrosis factor-alpha (TNF-a) use for inflammatory bowel disease. Inflamm Bowel Dis 2011, 17:479-484.

44. Bazzani C, Filippini M, Caporali R, Bobbio-Pallavicini F, Favalli EG, Marchesoni A, Atzeni F, Sarzi-Puttini P, Gorla R: Anti-TNFa therapy in a cohort of rheumatoid arthritis patients: clinical outcomes. Autoimmun Rev 2009, 8:260-265.

45. Favalli EG, Desiati F, Atzeni F, Sarzi-Puttini P, Caporali R, Pallavicini FB, Gorla R, Filippini M, Marchesoni A: Serious infections during anti-TNFa treatment in rheumatoid arthritis patients. Autoimmun Rev 2009, 8:266-273.

46. Deane S, Meyers FJ, Gershwin ME: On reversing the persistence of memory: hematopoietic stem cell transplant for autoimmune disease in the first ten years. J Autoimmun 2008, 30:180-196.

47. Saag KG, Teng GG, Patkar NM, Anuntiyo J, Finney C, Curtis JR, Paulus HE, Mudano A, Pisu M, Elkins-Melton M, Outman R, Allison JJ, Suarez Almazor M, Bridges SL Jr, Chatham WW, Hochberg M, MacLean C, Mikuls T, Moreland LW, O'Dell J, Turkiewicz AM, Furst DE; American College of Rheumatology: American College of Rheumatology 2008 recommendations for the use of nonbiologic and biologic disease-modifying antirheumatic drugs in rheumatoid arthritis. Arthritis Rheum 2008, 59:762-784.

48. Lok AS, McMahon BJ: Chronic hepatitis B: update 2009. Hepatology 2009, 50:661-662.

49. Ghany MG, Strader DB, Thomas DL, Seeff LB: Diagnosis, management, and treatment of hepatitis C: an update. Hepatology 2009, 49:1335-1374.

50. Hou JK, Velayos F, Terrault N, Mahadevan U: Viral hepatitis and inflammatory bowel disease. Inflamm Bowel Dis 2010, 16:925-932.

51. Palmore TN, Shah NL, Loomba R, Borg BB, Lopatin U, Feld JJ, Khokhar F, Lutchman G, Kleiner DE, Young NS, Childs R, Barrett AJ, Liang TJ, Hoofnagle $J H$, Heller T: Reactivation of hepatitis B with reappearance of hepatitis B surface antigen after chemotherapy and immunosuppression. Clin Gastroenterol Hepatol 2009, 7:1130-1137.

52. Davern TJ, Chalasani N: Drug-induced liver injury in clinical trials: as rare as hens' teeth. Am J Gastroentero/ 2009, 104:1159-1161.

53. Dart RC, Green JL, Kuffner EK, Heard K, Sproule B, Brands B: The effects of paracetamol (acetaminophen) on hepatic tests in patients who chronically abuse alcohol - a randomized study. Aliment Pharmacol Ther 2010, 32:478-486

54. Ramos-Casals M, Roberto Perez A, Diaz-Lagares C, Cuadrado MJ, Khamashta MA: Autoimmune diseases induced by biological agents: a double-edged sword? Autoimmun Rev 2010, 9:188-193.

55. Quintin E, Scoazec JY, Marotte H, Miossec P: Rare incidence of methotrexatespecific lesions in liver biopsy of patients with arthritis and elevated liver enzymes. Arthritis Res Ther 2010, 12:R143.

56. Raimondo G, Pollicino T, Cacciola I, Squadrito G: Occult hepatitis B virus infection. J Hepatol 2007, 46:160-170

57. Jansen TL: When rheumatology meets hepatology: are anti-TNFs safe in hepatitis B virus carriers? Arthritis Res Ther 2010, 12:103.

58. Calabrese $L H$, Zein NN, Vassilopoulos D: Hepatitis B virus (HBV) reactivation with immunosuppressive therapy in rheumatic diseases: assessment and preventive strategies. Ann Rheum Dis 2006, 65:983-989.

59. Yaniv I, Ash S, Farkas DL, Askenasy N, Stein J: Consideration of strategies for hematopoietic cell transplantation. J Autoimmun 2009, 33:255-259.

60. Kushida T, Ueda Y, Umeda M, Oe K, Okamoto N, lida H, Abraham NG, Gershwin ME, Ikehara S: Allogeneic intra-bone marrow transplantation prevents rheumatoid arthritis in SKG/Jcl mice. J Autoimmun 2009, 32:216-222.

61. Singh JA, Christensen R, Wells GA, Suarez-Almazor ME, Buchbinder R, LopezOlivo MA, Tanjong Ghogomu E, Tugwell P: Biologics for rheumatoid arthritis: an overview of Cochrane reviews. Cochrane Database Syst Rev 2009, 4:CD007848.

62. Nurmohamed MT: Newer biological agents in the treatment of rheumatoid arthritis: do the benefits outweigh the risks? Drugs 2009, 69:2035-2043.

doi:10.1186/ar3319

Cite this article as: Selmi C, et al.: Liver involvement in subjects with

rheumatic disease. Arthritis Research \& Therapy 2011, 13:226. 